\title{
El habla fronteriza en Estrella de la calle sexta de Luis Humberto Crosthwaite
}

\author{
Josefina Elizabeth Villa*
}

\section{Resumen:}

Conformado por la reformulación de dos sustancias: expresión y contenido, Estrella de la calle sexta deviene símbolo estético literario. Como símbolo suspende el valor referencial y no garantiza correspondencia entre lo enunciado y el mundo externo. Sin embargo, dado que está construida sobre la organización cultural de la realidad fronteriza, la obra literaria mantiene una tensión con la existencia concreta "del sentido común". Esto le permite ser interpretada como "literatura de la frontera" pero también funcionar como un modelo de expresión colectiva. En este trabajo enfatizaremos la función del habla como el material constructivo que singulariza esta narrativa y además como el vehículo que expresa la modelización literaria de una comunidad fronteriza.

Palabras clave:

Símbolo estético, lengua, habla, reformulación estética, literatura fronteriza.

\section{Introducción}

Si consideramos a una obra literaria como un signo diríamos, siguiendo a Hjelmslev, que está conformada por dos elementos

\footnotetext{
* Universidad Autónoma de Baja California.
} 
(funtivos) que son llamados expresión y contenido, los cuales son solidarios y se presuponen necesariamente. Sin embargo, las obras literarias no se reducen a su explicación como signo puesto que, al contrario de lo que ocurre con este, suprimen su relación con el referente y con los valores de verdad y falsedad que pudieran atribuírsele. La obra literaria constituye no un signo sino un símbolo estético (Prada 198).

Un símbolo se produce mediante una reformulación estética, procedimiento que, por un lado, toma la lengua cotidiana como sustancia para formar el plano de la expresión y por otro, toma la sustancia del mundo codificado como "real" por el sentido común para formar el plano del contenido. Expresión y contenido son rearticulados con una intencionalidad estética que constituye el símbolo. De esta manera se instaura una clase de discurso diferente que si bien es deudor de la lengua y el mundo del sentido común no garantiza una fidelidad a ellos.

Renato Prada señala dos funciones primordiales de la lengua: como medio de comunicación que es capaz de crear significados y como sistema modelizador. Además de transmitir información la lengua nos muestra un modo de ver la realidad; introducirnos a una lengua es conocer también su forma particular de apropiación del mundo. Asumiremos aquí el conjunto de relatos Estrella de la calle sexta como un símbolo estético que se construye mediante la modelización de las sustancias de la expresión y del contenido tomadas ambas de la realidad fronteriza. Dado que provienen de ella, los planos que conforman el símbolo mantienen en todo momento una tensión con la realidad concreta, no ficcional pues re-crean el paradigma de la identidad con que se reconoce a la cultura del norte de México, especialmente la que se manifiesta en la frontera con los Estados Unidos. Tal relación, realidad-mundo ficcional, permite el mecanismo de la interpretación pero no es debido a las coincidencias entre ambos que la obra adquiere valores estéticos que la singularizan. Estrella de la calle sexta es una obra singular no porque sea posible entre ella y el mundo cotidiano del sentido común una serie de verificaciones y constataciones sobre la "realidad fronteriza". Lo destacable literariamente en esta obra es el ejercicio menor de la 
lengua que se instaura dentro de ella y que, al producir una ilusión de realidad, crea también un mecanismo de fuga mediante el cual la hegemonía de la lengua expande los límites de la expresión.

De acuerdo con algunas de las consideraciones que desarrollan Deleuze y Guattari en Kafka, por una literatura menor, solo la literatura que instaura desde dentro de sí un ejercicio menor de la lengua es capaz de convertirse en una maquinaria de expresión colectiva (32). Por ejercicio menor de la lengua se entiende la literatura que usa la expresión de una minoría dentro de una lengua literaria mayor. Por lengua mayor entenderíamos en México cierta literatura que excluye de sí las variantes dialectales de su propia lengua, con lo cual se crea la ilusión de una uniformidad lingüística y se establece una separación entre la lengua literaria y el habla. Deleuze y Guattari explican que el atributo menor no califica ya a ciertas literaturas sino a las condiciones revolucionarias de cualquier literatura en el seno de una literatura mayor o establecida (31). La condición que califica a Estrella de la calle sexta como parte de una literatura menor es el uso de elementos particulares en su expresión que sirven de vehículo para manifestar el modelo de conciencia de una comunidad fronteriza.

\section{El problema de la lengua en la literatura fronteriza}

Desde que el habla de la periferia norteña se incorporó en la literatura se abrió la discusión acerca de su pretendido realismo. Con argumentos a favor y en contra la nueva literatura escrita por narradores y poetas radicados en los estados del norte apostó por una construcción del discurso que recreara o imitara los aspectos orales de su habla. (Quizá esta sea la más sobresaliente de sus innovaciones estilísticas y también la que logró convertirla en un producto de fácil clasificación en el mercado editorial). A nuestro parecer, la nueva reformulación del lenguaje que incluye a los regionalismos del norte forma parte de un movimiento que busca incorporar un nuevo horizonte sociocultural en la dinámica históricamente centralista de nuestro país. Lo interesante de este fenómeno está en que a pesar de haber existido grandes figuras literarias oriundas del nor- 
te de México como Julio Torri o Enriqueta Ochoa, es a partir de la escritura con marcas regionalistas de algunas de las obras de Eduardo Antonio Parra, Elmer Mendoza y Luis Humberto Crosthwaite, entre otros, que la crítica diserta sobre la "realidad" del norte mexicano. Escritores como Ricardo Elizondo o Federico Campbell habían introducido elementos semánticos que figuraban la región norteña en sus obras pero sin utilizar los recursos del habla en la articulación del discurso.

Que la crítica se atreva a discutir, a partir de la escritura de autores como Luis Humberto Crosthwaite, cuál es la "realidad" del norte mexicano, es algo significativo puesto que tal preocupación confirma que el lenguaje es lo que determina gran parte del sentir de toda una región circunscrita al territorio nacional. Significa también que incorporar el habla fronteriza a la literatura es incorporar, sobre todo, un modelo de mundo, una de las variadas formas de apreciación de la realidad que existen en México.

La discusión acerca de la existencia de una literatura de la frontera ha llevado implícita la suposición de que existe un mundo real del cual el discurso estético es una imagen. Esta premisa tiene su origen en la interpretación de la mímesis aristotélica como una propuesta de un modelo existente y no como la imitación de cierta estructura lógica de la realidad. La primera interpretación ha hecho que la mayoría de los estudios académicos que se ocupan de las obras producidas por los narradores del norte de México se dediquen a indagar "las imágenes estereotipadas del espacio fronterizo" (Mora 157) en las representaciones ficcionales sin ocuparse de señalar las características estéticas que las hacen singulares. Una de esas características es que la mayoría de las obras que integran el "corpus" literario de la frontera intentan crear, como señalaba Roland Barthes, una ilusión de realidad. Hay que señalar que el uso de los recursos que crean la ilusión referencial tiene una función específica que, como decía Tinianov, busca también su forma especifica. En Estrella de la calle sexta es, además de la mención de topónimos, la reformulación del habla lo que echa a andar la función constructiva de los elementos formales. 


\section{La ilusión de realidad}

En el ensayo El efecto de realidad Roland Barthes dice que una obra artística produce un efecto de realidad cuando crea una ilusión referencial. Esto es, cuando utiliza mecanismos que suprimen la connotación a favor de la denotación. La ilusión referencial funciona como un haber estado alli que se construye a partir de la utilización de referentes concretos que tienen una existencia "verdadera" en el mundo del sentido común. Son recursos o procedimientos: "cuyo estudio global todavía no ha sido emprendido, [entre ellos] se puede notar, por ejemplo, el anclaje espacio-temporal (empleo de topónimos y/o cronónimos que producen la ilusión de la 'realidad')" (Greimas 337).

En los tres relatos incluidos en Estrella de la calle sexta se mantiene una tensión con la realidad concreta de la frontera norte de México, particularmente con la región Tijuana-San Diego, a través de dos recursos importantes: la utilización de topónimos y la reelaboración del habla fronteriza; la reformulación de ambos produce la ilusión de realidad.

\section{a) La ciudad real como espacio diegético}

El espacio fronterizo existente entre dos naciones (México-Estados Unidos) es utilizado como escenario para desarrollar la diégesis de los relatos contenidos en la obra Estrella de la calle sexta. El espacio tematizado en las narraciones que analizamos es un mundo ficcional creado que utiliza recursos tales que producen un efecto de realidad. Por principio de cuentas diremos que estamos frente a tres historias que comparten referentes comunes en cuanto a la espacialidad. La primera de ellas se llama "Sabaditos en la noche" y se desarrolla principalmente en una calle turística llamada avenida Revolución. La segunda de ellas es "Todos los barcos" y narra el rito de paso de un joven norteamericano y su arribo a la adultez en uno de los bares de la misma avenida. La tercera de ellas, más compleja estructuralmente, y titulada "El gran pretender", narra las aventuras del Barrio $17 \mathrm{y}$ sus protagonistas anclados en una sociedad que se revela fronteriza. Las tres historias se desarrollan en un espacio público abierto: la 
calle. Es en este lugar donde se sitúan las acciones de los personajes. En la calle un hombre da cuenta de su ser en el mundo: "Hey, hey, aquí nomás mirando pasar a las beibis. Todos los sábados me encuentras sentadito en esta esquina, tripeando, agarrando mi cura" (Crosthwaite 13); también es en la calle donde un joven emprende el camino que lo llevará a transformarse en adulto: "Rumbo a la avenida Revolución. Peregrinaje. Alrededor las ofertas, el comercio: artesanías, cigarros, taxi-taxi, señoras pidiendo limosna con bebés amarrados a sus espaldas. El camino está sucio" (69). Y, en el último de los relatos, es la calle el sitio de reunión donde un grupo de personajes se reúne para hablar de las glorias pasadas del Barrio: "Por eso los morros se juntan en la misma esquina donde se reunían el Saico, el Mueras, el Chemo y el resto de la clica para hablar de los rucos, los cholos viejos, los que se fueron, los que se quedaron" (82). La calle es el topos que configura el espacio ficcional ideal para el devenir de la historia. La calle, la suma de las calles, articula a su vez un espacio mayor: la ciudad.

$\mathrm{Al}$ respecto de cómo se revela un espacio en la ficción, Mieke Bal dice que es durante la presentación de la fábula cuando los lugares son vinculados a ciertos puntos de percepción. Los puntos de percepción pueden darse por un personaje que observa y reacciona ante él o también puede ser "anónimo" (y creemos que se refiere al dado por el narrador). Consideramos los siguientes como puntos de percepción que articulan el espacio:

Te voy a decir cómo es esta calle, cómo es mi esquina, cómo es la raza que pasa por aquí en las noches. . . . la calle es una línea recta, sucia, rodeada de cantinas, farmacias, hoteles, congales, restaurantes y muchísimos lugares que venden artesanías. No tiene una iglesia o una cruz roja que la redima y la salve del infierno cuando se muera. Mi esquina está en la Calle Sexta, no es distinta a otras esquinas (21).

Arriba, bares con terraza. Muchachos y muchachas gritando y bailando. Besándose. En las banquetas, señoras pidiendo limosna, bebés atados a sus espaldas; señoras en el piso, ofreciendo pulseritas, artesanías. Two for dollar (71). 
Agua cayendo sobre el Barrio... Un arroyo atraviesa la calle. Algunos morritos salen sin que sus jefas se den cuenta, hacen barcos de papel. . . . Cuando las calles del Barrio se ponen así, no hay ninguna ranfla que pueda entrar. Se resbalan, se atascan. Los cholos cansados, que apenas regresan del jale, estacionan su ranflas en las orillas, junto a la casa del Pancho. . ahí se quedan largo rato, mientras pasa la lluvia, pisteando, cotorreando (102-03).

El primer ejemplo tomado de Sabaditos en la noche es la percepción de un personaje, en este caso del narrador-personaje, quien describe el espacio que habita los fines de semana y en donde se desarrolla la narración. Los dos siguientes párrafos son percepciones "anónimas" dadas por el narrador y solo en el segundo caso dicha percepción está focalizada por la mirada del joven que atraviesa la avenida para dirigirse a uno de los bares.

En la articulación del espacio también se utilizan topónimos y sitios con nombres propios: la avenida Revolución, el bar Blue Note, el salón de baile La Estrella, las tortas El turco, el Nicte-Ha, Southwestern College; así como los nombres de lugares geográficos: Tijuana, Tecate, San Diego, Los Ángeles, el Cerro del Cuchumá, la colonia Cacho. La utilización de estos lugares con nombre propio en los tres relatos es uno de los mecanismos por medio de los cuales se crea la ilusión referencial o efecto de realidad. Estos nombres deben su inclusión en la narración a la necesidad de articular un espacio producto de la suma de todos ellos. Las calles, los nombres de sitios recreativos, los lugares geográficos adyacentes delimitan lo dentro-fuera e imitan un modelo de organización urbana que, como en este caso, puede tener un referente extratextual (Pimentel, Espacio 63).

La ciudad articulada en Estrella de la calle sexta no es, como lo han querido ver algunos críticos, la ciudad de Tijuana en sí misma. Es una re-creación independiente que toma de la realidad su estructura o, diremos mejor, cierta estructura, ya que la disposición de una ciudad tan compleja como Tijuana no se limita a una sola avenida. Dice Philippe Hamon: "la descripción es re-escritura de otros sis- 
temas de clasificación ... reticulación de un extratexto" (cit. en Pimentel, Espacio 65). La ilusión de realidad se produce debido a que un sistema descriptivo, al articular un espacio, hace uso de modelos culturales previos que organizan el mundo. La ciudad de Tijuana, en el objeto de nuestro análisis, es una construcción que funda ficcionalmente otra ciudad, agregando o jerarquizando nuevos valores, nuevos significados en torno a una intencionalidad estética.

\section{b) Una isotopía fonoprosódica}

Las marcas regionales en la literatura, por la ley de la isomorfía, se manifiestan tanto en el nivel de la expresión como en el contenido. Podríamos decir que estas marcas son vínculos semióticos que se presentan como expresiones lingüísticas regionales a nivel fonético, sintáctico, semántico, pragmático y la "referencialidad" al menos virtual a "hechos", personas típicas de la región, fenómenos atmosféricos y costumbres (Prada 90). Estas marcas regionales otorgan una coherencia al discurso porque trazan líneas de significación por medio de redundancias temáticas o fonéticas que son llamadas isotopías. En un texto podemos encontrar diferentes líneas temáticas que forman una red isotópica. Esta red influye en la percepción de la obra artística creando un efecto de uniformidad en su lectura (Greimas 337). Una isotopía que se construye sobre el plano de la expresión Greimas la llama isotopía fonoprosódica.

¿Cómo localizar las isotopías en Estrella de la calle sexta? Umberto Eco responde: descubriendo las reglas que construyen su coherencia (144). Una línea de significación en esta obra la constituye la recurrencia de sintagmas que utilizan en su construcción la fonetización de vocablos o frases del idioma inglés:

Así que es un buen contrato éste que firmamos: el uno para el otro, meid for ich óder (15).

Mi patrón, ese güey sí es gringo, para que veas, a pein in da faquin as (16).

Calmado, carnal, yastuvo, deje algo pa más al rato, qué pues, se está poniendo usté muy saico (94).

Trabajaba de carrocero en el Otro Saite (112). 
En los ejemplos que citamos ciertos elementos de una oración están escritos haciendo una imitación de la pronunciación fonética de un idioma extranjero. Aunque la mayor parte de las oraciones está construida por palabras en español, y siguiendo su lógica sintáctica, al final de ellas el sentido se completa con los vocablos del idioma inglés.

Una regla de coherencia de esta isotopía está presente en la utilización de actos del habla fronterizos que toman palabras de un idioma extranjero a manera de préstamos lingüísticos para elaborar un caló propio. Sobre estos actos del habla típicos de la frontera norte de México, en concreto en la ciudad de Tijuana, se han realizado estudios empíricos lingüísticos de los que se ha concluido que los dos fenómenos producto del contacto entre el español y el inglés en esta frontera son dos: la lexicalización de préstamos del inglés y el cambio de código (Valencia 18). El préstamo lingüístico es "la introducción de palabras o frases idiomáticas cortas de una lengua en otra, que se incorporan al sistema gramatical de la lengua receptora y que el hablante trata como parte del léxico de ésta”. A diferencia del cambio de código, que es un fenómeno de alternancia, los préstamos léxicos provenientes del inglés tienen un alto grado de integración verbal al español (23).

Lo interesante de este fenómeno lingüístico está en que su uso pone en evidencia la coexistencia de dos culturas, la mexicana y la norteamericana, que comparten espacios de intersección donde se producen diálogos entre sus textos.

Una característica que singularizó a la narrativa de Crosthwaite desde sus primeras publicaciones fue la construcción de un discurso que tomaba préstamos léxicos del idioma inglés sin recurrir a notaciones especiales al hacerlo. Este narrador fue uno de los primeros en convencionalizar en la literatura la lexicalización y fonetización de los préstamos lingüísticos del inglés al español en la literatura mexicana que tomaba como modelo de la realidad a los espacios territoriales fronterizos. En Estrella de la calle sexta, esta forma de apropiación participa como elemento constructor del discurso. Si bien las palabas tomadas del inglés no transforman sustancialmente el contenido semántico del sintagma lingüístico. Lo único que 
se produce con este fenómeno es, siguiendo a Saussure, que las palabras extranjeras "no existen más que por su relación y su oposición con las palabras que les están asociadas" (49). Por lo que la significación que acontece al encontrar construcciones articuladas con vocablos pertenecientes a dos idiomas distintos es que se trata de una manifestación lingüística, en este caso: una ocurrencia en el habla del español, que considera importantes sus relaciones con otra cultura, tanto como para dar cuenta de ellas en su expresión.

En principio, dice Lotman, toda la cultura es políglota puesto que siempre el origen de sus textos se produce en el cruce de por lo menos dos sistemas semióticos (Semiósfera 85). Si rastreamos el origen de todo concepto encontraremos que sus raíces provienen siempre del intercambio entre varios lenguajes. El automatismo que produce la familiaridad con que vemos cotidianamente a los actos culturales hace que "desaparezca" este origen políglota natural. Pero el lenguaje fronterizo, como acto particular que acontece dentro del medio semiótico, revela el originario dinamismo de la cultura y pone en marcha otros procesos generativos de sentido (90). El lenguaje fronterizo se convierte así en: a) manifestación y sentir de una identidad colectiva y b) sustancia de la expresión con la que pueden elaborarse discursos de modelización secundaria como el discurso estético.

Una regla de coherencia isotópica en el plano de la expresión está, entonces, en la recurrencia de los intercambios lingüísticos entre dos idiomas para formar un solo mensaje. Otra regla de coherencia que advertimos en los tres relatos de Estrella de la calle sexta es el uso de elementos de las literaturas orales para crear un efecto testimonial en el discurso.

De acuerdo con Renato Prada, la literatura testimonial tiene una remota tradición en América Latina. Su misión, desde la conquista, fue testimoniar sobre la verdad de los hechos por lo que siempre es intertextual, supone "otra versión o interpretación (otro texto) sobre su objeto (referente), una versión opuesta, contraria o distorsionada, a la cual corrige, se opone o rectifica" (Discurso 11). En Estrella de la calle sexta la referencialidad se suspende para crear un símbolo estético. Sin embargo, hay ciertos elementos del discurso 
testimonial como la presentación de un narrador en primera persona que suponen la presencia de un receptor y que producen un efecto de oralidad. Tenemos varios ejemplos de esto:

He ganado muchos amigos, sentado por aquí. Batos desconocidos a veces llegan y se sientan conmigo. Como tú, como muchos otros que tienen ganas de platicar ... (18). $\mathrm{Y}$ es que el Nicte-Ha es el lugar. No hay otro donde un cholo pueda estar a gusto con su jaina y su música .... Y si tienes compitas en otras colonias pues ahí es cuando los saludas. Y si tienes alguna bronca con un güey de otro barrio, pues ahí es donde lo resuelves (122).

Ford Galaxie: el mejor carro del mundo. ¿Cuántos cholos caben en una ranfla de ese tamaño? Mejor ni preguntes (127).

Que se recurra a la oralidad como elemento para modelizar el mundo de la frontera norte de México puede deberse a la poca o nula tradición escrita que existe en esa región. A diferencia del centro del país las ciudades que se desarrollaron en la periferia no construyeron élites de poder intelectual que construyeran ideologías colectivas. ${ }^{1}$ Las ciudades del centro en cambio conjuntaron círculos de conocedores de las letras que fueron capaces de mantener e interpretar el aparato legal y jurídico que sostuvo el poder virreinal. A este selecto grupo de ilustrados Ángel Rama le llama La ciudad letrada. Este grupo de élite lo integraron intelectuales al servicio del poder que diseñaron modelos culturales destinados a la construcción de ideologías públicas. Además:

${ }^{1}$ La investigación de cómo se construyeron ideologías colectivas en la frontera norte es apenas incipiente y requiere de un trabajo historiográfico interdisciplinario. En Baja California, la literatura ha sido un vehículo constructor de ideologías públicas y un discurso sobre el que se han anclado mayormente las indagaciones sobre la identidad fronteriza. Ese es uno de los rumbos por el que se encaminan ahora mis investigaciones. 
Su supremacía se debió a la paradoja de que sus miembros fueron los únicos ejercitantes de la letra en un medio desguarnecido de letras, los dueños de la escritura en una sociedad analfabeta y porque coherentemente procedieron a sacralizarla dentro de la tendencia gramatológica constituyente de la cultura europea (33).

El desarrollo de las ciudades de la periferia del norte se debió más que nada al empuje y visión de productores empresarios con poca o nula tradición escrita y, sobre todo, a la migración de la clase trabajadora de diversas regiones del país; consecuentemente los primeros productos culturales elaborados a partir de una autoconciencia semiótica tienen la tendencia a privilegiar el habla natural sobre la tecnología de la escritura. ${ }^{2}$

\section{Un ejercicio menor de la lengua}

Saussure separa la lengua (langue) del ejercicio del habla (parole). Mientras que la lengua es la suma de imágenes verbales almacenadas en todos los individuos, el habla es un acto individual de voluntad e inteligencia. Así tenemos, para el caso que nos ocupa, una distinción de la lengua como la lengua española cuya existencia radica en la comunidad parlante de esta. La lengua española existe en virtud de un "contrato" colectivo establecido entre los miembros de la comunidad hispanohablante. La lengua es esa especie de "diccionario" que poseemos en cada uno de nuestros cerebros y que está regulada por una convención social que dicta la gramática y la ortografía correctas para su uso. Saussure equipara la lengua con una sinfonía cuya realidad es independiente de la forma en que se ejecute. La lengua, como la sinfonía, al ser ejecutada por los

${ }^{2}$ Sobre el privilegio del habla sobre la escritura en la tradición occidental, tomamos la idea de Jacques Derrida cuando señala que tal privilegio responde siempre a una necesidad histórica. 
hablantes sufre accidentes que producen actos lingüísticos de voluntad individual. Al ser enunciada la lengua se convierte en habla.

Cada acto particular de la lengua produce eventos fonéticos singulares que expresan una voluntad. Podríamos decir que el habla es la elección sintagmática que hacemos cuando decidimos comunicarnos utilizando el paradigma (código) dado por la lengua. Decíamos que en Estrella de la calle sexta el habla es reformulada para conformar el plano de la expresión, circunstancia en la que nos detendremos en esta última parte.

Si bien la lengua utilizada como código articula mensajes de diferente tipo, como el texto artístico, es verdad que al llevar estos mensajes a la escritura se incrementa su distancia con respecto a la lengua hablada; puesto que el escribir un texto de cualquier naturaleza implica someterlo a ciertas reglas gramaticales que condicionan su lectura. En la escritura de los tres relatos que integran la obra que nos ocupa hay, efectivamente, un condicionamiento del habla particular de la frontera. Sometida a reglas estéticas que producen un ritmo en el trayecto de lectura, el habla fronteriza construye una isotopía fonoprosódica que otorga una coherencia al discurso. Aunque no se trata de una imitación tal del habla fronteriza sino la imitación de una estructura dispuesta con el fin de producir efectos estéticos. Si debemos señalar, además, la importancia de esto último diremos que radica en que el habla fronteriza al ser incorporada a la escritura creativa contribuye a la renovación de los procedimientos con que se elabora la literatura en México.

El habla, en su uso cotidiano, modifica los hábitos lingüísticos y con esto interfiere en la evolución de la lengua. Hay una interdependencia entre ambas. La lengua es producto y a la vez instrumento del habla (Saussure 46). De ahí la incorporación paulatina que van haciendo los diccionarios de nuestra lengua de los vocablos que surgen del habla popular.

En México, las alteraciones o actualizaciones de vocablos lingüísticos de otros idiomas (indígenas o extranjeros) usados como elementos constructivos del discurso literario han sido recursos que modifican, y con razón, la recepción de las obras. De ahí procede la clasificación de la narrativa del norte en cuanto recurre al habla 
coloquial de una región geográfica para conformar el plano de la expresión (como sucedió con la novela "indigenista" de Rosario Castellanos o con la narrativa de la "onda" de José Agustín). El habla sirve como elemento constructivo que se opone, dentro del sistema de la obra particular, a otros recursos tradicionales como la trama, el estilo o la sintaxis. El habla de la frontera, para el caso que nos ocupa, es un recurso no tradicional que dota al texto artístico con un carácter innovador y que también se convierte en uno de los elementos dominantes de la obra.

El habla introducida como regionalismos, o en algún otro uso especial, en la lengua literaria aparece como ruido dentro de la gramática que regula el idioma. En los sistemas tradicionales de comunicación el ruido impide que los mensajes sean efectivamente transmitidos, pero en el arte el ruido es generador de nueva información. Estrella de la calle sexta es un texto construido sobre una estructura artística modelada sobre diferentes programas narrativos que introduce vocablos de otro idioma reformulados para seguir la sintaxis de la lengua española. La capacidad del arte de asimilar los vocablos extrasistémicos, ajenos a la lengua, permite que se generen nuevos significados que revelan la singularidad de esta obra. Pero, en este conjunto de relatos, el habla tiene, además de una ocurrencia particular de la lengua expresada con palabras, un contenido ideológico potencial.

Para Bajtín, la palabra es un signo de la conciencia, ella acompaña a todo acto ideológico. La palabra es material aunque también es un signo de uso interno; es decir, que puede usarse como signo sin necesidad de expresarse plenamente hacia el exterior. De hecho, para Bajtín, todos los signos que tienen un contenido ideológico son materiales. La ideología no radica en la conciencia individual sino que es el producto de una relación entre materiales sígnicos. La conciencia surge a través de una cadena que une la comprensión entre un signo y otro, sucesivamente: "No existen rupturas, la cadena jamás se sumerge en una existencia interior no material, que no se plasme en un signo" (34). De esta manera, Bajtín niega la existencia de una conciencia individual: 
El signo sólo puede surgir en un territorio de interindividualidad, territorio que no es "natural" en el sentido directo de esta palabra: el signo tampoco puede surgir entre dos homo sapiens. Es necesario que ambos individuos estén socialmente organizados, que representen un colectivo: sólo entonces puede surgir entre ellos un medio sígnico (semiótico) (35).

En tanto que la ideología es el resultado de esa comprensión de la cadena sígnica, la conciencia es colectiva. (Recordemos que el signo surge mediante una convención e interacción social). Si la palabra es signo de la conciencia entonces podemos decir que el habla fronteriza no solo funciona como material constructivo de la obra sino que también es un vehículo que expresa el modelo literario de una ideología colectiva:

En la palabra se ponen en funcionamiento los innumerables hilos ideológicos que traspasan todas las zonas de la comunicación social. Por eso es lógico que la palabra sea el indicador más sensible de las transformaciones sociales, inclusive de aquellas que apenas van madurando, que aún no se constituyen plenamente ni encuentran acceso todavía a los sistemas ideológicos ya formados y consolidados (44).

Los actos de la palabra registran las fases transitorias de las transformaciones sociales. Esto último coincide con la idea de Saussure acerca de que en el habla se produce la evolución de la lengua. Así, tenemos que el registro de una forma particular de utilización del lenguaje en México, su reelaboración como sustancia de la expresión de un producto artístico, lo convierte en un vehículo ideológico que refracta ${ }^{3}$ la realidad. El signo que es la palabra re-

${ }^{3}$ Cuando nos referimos a que el signo refracta la realidad seguimos la idea de Bajtín, para quien la refracción es aquella "operación" que realiza el signo al representar, reflejar, sustituir o distorsionar lo que está fuera de él mismo; lo que se encuentra más allá de su materialidad. 
fracta la realidad a su modo; esto es, que puede modificarla o serle fiel o bien "percibirla bajo un determinado ángulo de visión" (33). Esta es otra de las razones por la que las interpretaciones críticas de la literatura del norte de México tienen, como hemos dicho ya en otra parte, una necesidad de hacer verificaciones entre la obra y el mundo del sentido común.

Pero, ¿qué registra? ¿Cuáles son esas "fases transitorias de las transformaciones sociales"? La incorporación del habla fronteriza como recurso de construcción contribuye a configurar una identidad colectiva dentro de la literatura que, hasta antes de la generación de sus propios productos culturales, aparecía como una variante difusa de la identidad mexicana. También ésta es otra razón, así lo creemos hasta ahora, para estudiar las refracciones que produce el habla particular (como signo constructor dentro de la literatura) de muchas de nuestras regiones en México.

Para que un producto cultural del norte de México pudiera formar parte del horizonte social de nuestra mexicanidad y suscitara, en palabras de Bajtín, "una reacción semiótico-ideológica" (47), fue necesario que se produjera un proceso de descentramiento en el poder económico que desde la Colonia imperaba en el centro del país. La migración hacia el norte y el consecuente abandono del campo; así como el progreso de una lógica terrible de la ilegalidad, que posibilitó el mercado del narcotráfico, han modificado las bases de nuestra economía reubicando los centros de poder y modificando la existencia material de todo un pueblo. Esta quizá sea una respuesta - y una respuesta nada deseable - a la súbita toma de conciencia que cobró la periferia del norte mexicano en las últimas tres décadas y que ha dado pie al surgimiento de algunos de sus más notables productos culturales.

La integración del norte de México, o mejor dicho: el modelo de su organización cultural, en el horizonte nacional ha puesto también en evidencia la existencia de reservas periféricas de significación que están en proceso de constituirse como discursos de identificación de una comunidad.

La identidad mexicana fue el resultado de un mestizaje entre dos herencias culturales. En torno a esta unidad mestiza se ha de- 
sarrollado el proyecto de nuestra nación. Aunque en la realidad el privilegio del ascendente extranjero domine, en el discurso somos una nación con valores mestizos que posee toda una iconografía cultural heredada a través de la práctica social y la educación formal. Sin embargo, el arribo de manifestaciones sociales como el neozapatismo y su consecuente revaloración del componente indígena, ha hecho que el proyecto modernizador de nación al que pertenecemos resulte insuficiente para explicar la realidad heterogénea del país. La modernidad, dice García Canclini, es una máscara: "Un simulacro urdido por las élites y los aparatos estatales, sobre todo los que se ocupan del arte y la cultura, pero que por lo mismo los vuelve irrepresentativos e inverosímiles" (21).

Una muestra de que el pretendido modelo de mestizaje ha sido irrepresentativo para la población es el fenómeno masivo de la migración campesina hacia los Estados Unidos. Los sectores discriminados por el inconsistente modelo mestizo en su camino hacia un ideal de superación han contribuido a poblar los espacios geográficos de la periferia norteña, generando con esto procesos de reterritorialización y desterritorialización: nuevas prácticas simbólicas acontecen en los espacios poblados por el arribo de migrantes. Una característica de estas es la formación de hibridaciones que revelan su origen en el cruce de estructuras que antes estuvieron separadas.

Toda lengua, en tanto que sistema, contiene elementos por los cuales la unidad que constituye se fuga. Son elementos que permiten expandir las posibilidades de su expresión. Tal sucede, por ejemplo, con los tropos, que expresan nuevas realidades utilizando la elasticidad semántica que habita en las palabras. Un elemento tensor de la lengua señala un movimiento hacia los extremos de esta, incluso rebasándola (Deleuze y Guattari 38). Los préstamos lingüísticos del inglés y su reformulación en Estrella de la calle sexta, son elementos tensivos de la lengua que constituyen el habla fronteriza con la que se ha elaborado un símbolo estético. Son, además, elementos constructivos por donde se fuga la hegemonía de la lengua para expandir sus propias fronteras. 


\section{Bibliografía}

Bal, Mieke. Teoría de la narrativa (una introducción a la narratología). Tr. Javier Franco, 8a ed., Cátedra, 1987.

Barthes, Roland. El susurro del lenguaje: más allá de la palabra y la escritura. Tr. C. Fernández Medrano, Paidós, 2000.

Crosthwaite, Luis Humberto. Estrella de la calle sexta. Tusquets Editores, 2000.

Derrida, Jacques. De la gramatología. Traducción de Oscar del Barco, $6^{a}$ ed. Siglo veintiuno editores, 2000.

De Saussure, Ferdinand. Curso de lingüística general. Tr. Mauro Armiño, $3^{a}$ ed. Fontamara, 2011.

Deleuze, Gilles y Félix Guattari. Kafka: por una literatura menor. Tr. Jorge Aguilar, Era, 1978.

Eco, Umberto. Lector in fabula: la cooperación interpretativa en el texto narrativo. Tr. Ricardo Pochtar, $4^{a}$ ed., Lumen, 1999.

García Canclini, Néstor. Culturas híbridas: estrategias para entrar y salir de la modernidad. Grijalbo, 1989.

Greimas, Algirdas Julien y Joseph Courtés. Semiótica: diccionario razonado de la teoría del lenguaje. Traducción de Enrique Ballón Aguirre, Gredos, 1982.

Hjelmslev, Louis. Prolegómenos a una teoría del lenguaje. Tr. José Luis Díaz de Llano, $2^{a}$ ed., Gredos, 1974.

Lotman, Iuri. Estructura del texto artístico. Tr. Victoriano Imbert, $2^{\mathrm{a}}$ ed., Istmo, 1982.

- La semiósfera I: semiótica de la cultura y del texto. Tr. Desiderio Navarro, Cátedra, 1996.

Mora, Sergio. La representación del espacio fronterizo mexicano en la narrativa mexicana y mexicoamericana: 1974-1998. 2005. U. de Arizona, disertación de doctorado.

Pimentel, Luz Aurora. El relato en perspectiva: estudio de teoría narrativa. Siglo veintiuno, 1998.

- El espacio en la ficción. Ficciones espaciales: La representación del espacio en los textos narrativos. Siglo veintiuno, 2001.

Prada, Renato. El lenguaje narrativo: prolegómenos para una semiótica narrativa. Universidad Autónoma de Zacatecas, 1991. 
- Literatura y realidad. Fondo de Cultura Económica, 1999.

- El discurso-testimonio y otros ensayos. Universidad Nacional Autónoma de México, 2001.

Rama, Ángel. La ciudad letrada. Ediciones del norte, 1984.

Jakobson, Roman, Teoría de la literatura de los formalistas rusos. Tr. Ana María Nethol, $7^{a}$ ed., Siglo veintiuno, 1995.

Valencia, Valeria. "Veintidós préstamos léxicos del inglés en el dialecto del español tijuanense". Plurilinkgua, vol. 11, n² 2, 2015, pp. 15-33.

Voloshinov, Valentín. El marxismo y la filosofía del lenguaje: los principales problemas del método sociológico en la ciencia del lenguaje. Tr. Tatiana Bubnova, Alianza editorial, 1992. 